\title{
Etnografiar las migraciones 'Sur'- 'Norte': la inscripción en nuestros cuerpos de representaciones de género, raza y nación.
}

To do an Ethnography 'South-North' Migrations: Gender, Race and Nation signed up on our bodies.

\section{CARMEN GREGORIO GIL}

Universidad de Granada carmengg@ugr.es (ESPAÑA)

Recibido: 27.10 .2016

Aceptado: 13.02 .2017

\section{RESUMEN}

Desde mi preocupación por la teorización de las articulaciones entre las diferenciaciones sociohistóricas de género, raza, cultura e inmigración, me propongo en este trabajo compartir mi experiencia etnográfica de trabajo de campo multilocalizado (Marcus 1995). Entendiendo con Okely $(1975,1992)$ que lo personal no sólo es político, sino también teórico (Gregorio 2006:32) trato, siguiendo a Jone Miren Hernández, de "habitar" en mi etnografía para entenderla “...como experiencia de la antropóloga relacionada con actitudes culturales presentes en la sociedad y no como expresión 'del conocimiento' abstracto, impersonal, descontextualizado" (Hernández 2012: 1). De esta forma pretendo restituir el valor del conocimiento desde nuestros propios cuerpos, como sujetos de acción que experimentan, sienten y se emocionan, cuestión controvertida, al confrontar con el dogma de la neutralidad y objetividad que se le presupone a todo conocimiento científico.

\section{PALABRAS CLAVE}

Etnografía feminista, género, raza, República Dominicana.

\section{ABSTRACT}

TThis article considers the problematic of the connections between gender, race, culture and migrations spanning different historic.al and social conside- 
rations. My principal aim is to share my expectations and experiences making ethnography during the time of my multi-localized fieldwork (Marcus, 1995). I argue, according to Okely that personal is not only political $(1975,1992)$, but also is theorical (Gregorio 2006:32). Relatedly, I try to "live" (following Jone Miren Hernández) my own ethnography, in order to understand it as "the experience of the anthropologist related to cultural attitudes of a certain society and not as expression of "the knowledge", which can be abstract, impersonal and lacks of context. (2012:1). In this way, I try to give back the value of knowledge to our body's experience as subjects which experiment, feel and get emotions; in direct confrontation with the typical neutrality and objectivity dogmas of the "scientific knowledge".

\section{KEY WORDS}

Ethnography Feminist, Gender, Race, Dominican Republic.

\section{INTRODUCCIÓN}

Inscribo este trabajo en el campo de la antropología social feminista, enfoque teórico y epistemológico surgido en los años 70, desde el que se vienen haciendo relevantes contribuciones a la identificación y análisis de los procesos mediante los que se produce la diferencia y la desigualdad ${ }^{1}$. Este enfoque ha venido guiando mis trabajos de investigación, que arrancan en los años 90 con el análisis de las migraciones internacionales desde el 'Sur' al 'Norte' como procesos generizados, enraizados en la producción de desigualdades sociohistóricas y geopolíticas encarnadas en diferenciaciones socioculturales de 'género', pero también de 'raza', ‘cultura' y ‘nación' (Gregorio 1998, 1999, 2006b).

Procesos generizados, porque no podemos ignorar el contexto de creciente feminización de la pobreza generada por las políticas económicas neoliberales. Dichas políticas, precarizan la mano de obra y vienen acompañadas de recortes en los servicios públicos (salud, educación, vivienda, infraestructuras) que provocan el aumento del trabajo doméstico y de cuidado. Procesos generizados,

${ }^{1}$ Para adentrarse en esta perspectiva contamos con el ya clásico texto de Henrietta Moore "Feminism and Anthropology" de 1988, traducido al castellano en su primera edición en 1991, desde el que se aborda el surgimiento y significado de la corriente crítica feminista en Antropología social, así como algunas de sus aportaciones más relevantes al campo de la economía, el parentesco, la política. Otros trabajos que tratan de situar esta perspectiva son los de Thurén (1993) Narotzky (1995) Méndez (2007) y las compilaciones de Del Valle (2000) y Gregorio y Castañeda 2012, ésta última para el contexto latinoamericano.

${ }^{2}$ Desde una perspectiva Marxista y de la Economía política utilizamos las categorías 'Sur''Norte', al objeto de enfatizar el carácter construido de tales distinciones y llamar la atención acerca del desigualitario orden global capitalista, que produce los movimientos de población de la 'Periferia' al ‘Centro' del 'Sistema Mundo', siguiendo la terminología de Wallerstein. 
en tanto sacan a la luz el trabajo no pagado y fuertemente naturalizado que venían realizando las madres, esposas e hijas y en el caso del estado español, a la incorporación de las mujeres al mercado de trabajo se une un sistema de bienestar familista 3 .

La denominada feminización de las migraciones, sin duda, ha visibilizado un fenómeno nuevo en la vieja Europa: la "crisis de los cuidados"4. La transcendencia de los cuidados para la sostenibilidad de la vida ${ }^{5}$ se ha hecho visible en los circuitos del mercado transnacional, en todas sus dimensiones: afectivas, materiales y sociales, y porque no decirlo, sexuales, pasando incluso a ser objeto de lucro en el mercado global capitalista, en esta última dimensión 6 . Las lógicas del mercado transnacional se asientan en la lógica binaria de género, produciendo cuerpos válidos para la 'reproducción' y cuerpos válidos para la 'producción'. Si bien, en el nuevo contexto global, las fronteras de género establecidas mediante la separación de la esfera reproductiva o 'doméstica' ${ }^{7}$ y la esfera productiva ${ }^{8} \mathrm{o}$ 'laboral', fruto del 'contrato sexual' del modelo capitalista, se desdibujan. El mercado se inserta en la 'esfera doméstica', mediante la externalización del trabajo doméstico profundizando las lógicas de dominación de género con las de clase, raza, etnicidad y extranjería. En este contexto de migraciones transnacionales la imbricación de estas lógicas producen cuerpos-máquinas (des)generizados ${ }^{9}$, útiles en las relaciones de mercado, y

\footnotetext{
${ }^{3}$ Para un análisis de las concepciones de género subyacentes a las políticas públicas en el Estado español véase Comas (1995).

${ }^{4}$ Véase el apartado especial "la crisis de los cuidados" del Periódico Diagonal, 3 al 16 de marzo de 2005, pp:12-13 y los trabajos de "Precarias a la deriva" en la web de eskalera karakola http://www.sindominio.net/karakola/. Si bien, ante la noción más extendida de "crisis global de cuidados" creo necesario contextualizar esta crisis en "Europa”. Es en el proceso de construcción de social, económico y político de la Fortaleza Europa donde las nuevas divisiones de género junto con el déficit de reemplazo generacional, provocarán la demanda de mujeres en el 'mercado de los cuidados' más allá de sus fronteras. Estaría de acuerdo en plantear la crisis de 'sostenibilidad de la vida' en el sentido de Carrasco (1993) desde una política global feminista, en tanto crítica al modelo económico neoliberal y con esta intencionalidad hablar de la "crisis del cuidado o de los cuidados' pero considero necesario precisar el uso que hacemos del concepto cuidado(s) en cada contexto específico. Para una reflexión sobre el uso del "care" en el entorno europeo véase Martín Palomo (2009).

${ }^{5}$ La definición del trabajo de cuidado que planteo (Gregorio 2009) desborda su localización desde delimitaciones familiares y de parentesco, para entenderlo como responsabilidad social 'social care' (Daly \& Lewis 1999, Letablier 2007) y ética (Gilligan 1982) y como un continuo que incluye dimensiones materiales, emocionales, afectivas, corporales, sociales y éticas difícilmente separables (Carrasco 2003, del Valle 2003, Pérez Orozco 2006).

${ }^{6}$ Según Naciones Unidas el tráfico sexual constituye la tercera actividad ilegal más lucrativa del mundo después del tráfico de armas y el de drogas.

${ }^{7}$ Esfera de la reproducción de relaciones centradas en la provisión del bienestar material, social, afectivo, sexual dentro del 'hogar' y espacio femenino por excelencia.

${ }^{8}$ Esfera de la reproducción de las relaciones insertas en la lógica del mercado fuera del 'hogar', centro de la vida política y masculina por excelencia.

9 En ningún momento quiero sugerir la desaparición de las desigualdades de género, sino llamar la atención sobre la producción de cuerpos, que aun siendo sexuados como hombres y como mujeres, son requeridos para ser productivos en exclusividad, trato por tanto de repensar las categorías 'hombre' como categorías homogéneas, en su asociación con lo productivo y 'mujer' en su
} 
cuerpos feminizados, etnizados y proletarizados que transitan entre el hogar y el mercado, sobre quiénes se sostienen los cuidados. En las sociedades de consumo, menos el tiempo todo parece ser comprable y consumible, incluyendo las diferentes dimensiones del cuidado: el apoyo emocional y psicológico, el sexo, la protección, la atención a las necesidades de la vida diaria, el descanso, la comunicación, etc. Paralelamente los estados, debilitados en el control de los mercados, la evasión de impuestos y de capitales y la concentración de la riqueza, dirigen sus políticas al reforzamiento de las fronteras, convirtiendo la inmigración en la amenaza para el bienestar ${ }^{10}$, precisamente, del mismo que se exime proveer, estableciendo alianzas supranacionales al objeto de controlar que la mano de obra inmigrante, sea sólo eso, mano de obra, precarizada, excluida de los derechos sociopolíticos.

\section{ETNOGRAFÍA FEMINISTA}

Situarme en una etnografía feminista, en singular, constituye sin duda una opción epistemológica y política ${ }^{11}$. Si bien, cuando en mis clases de metodologías feministas surge la pregunta de ¿Cómo reconocer que una etnografía es feminista o no, o cómo hacer etnografía feminista? o incluso ¿Cómo establecer la diferencia entre etnografía y autoetnografía? ${ }^{12}$ Entro, en esa incomodidad que me produce saber que con nuestro magisterio podemos contribuir al establecimiento de terminologías clasificatorias de orden técnico, desprovistas de contenido político. Estando de acuerdo con Lila Abu-Lughod (1990) cuando se pregunta sobre la posibilidad de existencia de una etnografía feminista en su trabajo que lleva por título "Can there be feminist ethnography?" considero que es "tiempo de empezar una reflexión sobre las muchas maneras en las que podría ser" (1990:27) y en ese sentido, utilizo el plural "Etnografías feministas"13. Si bien, me gusta

asociación con lo reproductivo. Véase el desarrollo de esta idea en Gregorio 2009.

${ }^{10}$ En este contexto, de apertura y repliegue de fronteras, asistimos a la proliferación de discursos hacia la población inmigrante, representada como un 'otro/a' que amenaza nuestro supuesto bienestar. Para un análisis de las políticas de fronteras europeas, de la llamada "agenda Europea para la Migración" véase el trabajo de Francesco Vacchhiano (2015) "los hundidos y los salvados. Reflexiones sobre movilidad y frontera en tiempo de crisis.

${ }^{11}$ El debate sobre si existe o no una etnografía feminista es reciente en el estado español, si bien, no lo es en el contexto estadounidense, donde en 1988 Judit Stacey titulaba su trabajo "Can There be a Feminist Ethnography?" y Lila Abu-Lughod, por su parte, en ese mismo año dictaba una conferencia en el Departamento de antropología de la Academia de las Ciencias de Nueva York, que se publicaría dos años con el mismo título que el trabajo de Stacey (Abu-Lughod 1990).

${ }_{12}$ No quiero dejar de reconocer y agradecer a las alumnas de las diferentes promociones del "Máster Erasmus Mundus en Estudios de las Mujeres y del Género (GEMMA)" las inquietudes que me han despertado con sus preguntas y aportaciones, así como a mi compañera de curso Ana Alcázar.

${ }^{13}$ Reflexión a la que vengo animando junto con Ana Alcázar en el marco de las dos ediciones del Congreso de Antropología organizado por la AIBR en las que hemos coordinado el simposio propuesto con el título "Sobre las posibles maneras de practicar una etnografía feminista" y en el 
usar el singular y hablar de etnografía feminista a modo de reconocimiento de una genealogía de antropólogas, que por un lado se anticiparon al giro postmoderno utilizando una escritura reflexiva sin despojarla de las dimensiones emocionales de su experiencia etnográfica y por otro, pusieron en el centro del debate epistemológico las relaciones de poder en el trabajo de campo, nuestras posiciones situadas en la producción de intersubjetividad.

Como he señalado en otro lugar (Gregorio 2006:32) para la etnografía feminista lo emocional y lo personal no pueden ser separados de lo conceptual, como indica Okely (1975) no sólo lo personal es político ${ }^{14}$, también "lo personal es teórico". Pero además, desde esta perspectiva no perdemos el referente político del proceso de reflexividad inmerso en la práctica etnográfica. Con ello evidenciamos cómo la Ciencia parece proveernos de un lenguaje y una estructura conceptual para el análisis de la acción política, pero no para el análisis de los sentimientos que guían nuestras acciones, alejándonos de lo que es destacado por Scheper-Hughes utilizando las palabras de Sontang (1961) de "una amplia mirada a la condición humana, elaborada con total sensibilidad" (ScheperHughes 1983:115). Hecho que no vendría sino a mostrarnos una característica más de un pensamiento occidental escindido entre razón y emoción.

Como han dado cuenta diferentes autoras ${ }^{15}$, existen un buen número de etnografías escritas por antropólogas en los prolegómenos de la constitución del método etnográfico, en las que se incorpora la experiencia personal de la investigadora, esa "mancha subjetiva" desde la que se comparten perplejidades, dudas, temores, dilemas éticos, afectos y desafectos, ese yo que desde la etnografía tradicional es considerado un estorbo. Algunas de estas etnografías se anticiparon al giro postmoderno, si bien en el contexto en el que fueron escritas se consideraron más próximas al género literario que al científico ${ }^{16}$. Desde luego, estos trabajos supusieron una ruptura, al mismo tiempo que su marginación, al salirse de los convencionalismos que imponían borrar la subjetividad y evitar

que cabe mencionar el interés despertado en ambas ediciones. Reflexiones que estamos poniendo a conversar con la "etnografía colaborativa" desde la que están trabajando diferentes miembros del equipo del proyecto en el que ambas participamos ("Procesos emergentes y agencias del común: praxis de la investigación social colaborativa y nuevas formas de subjetivación política" Convocatoria 2014, proyectos de I+D, del programa estatal de fomento de la investigación científica y técnica de excelencia, CSO2014-56960-P).

${ }_{14}$ Parafraseando el eslogan "lo personal es político" promulgado desde la llamada tercera ola del feminismo radical de los años 60 , como fórmula que viene a sintetizar una concepción de la política, que cuestiona la concepción más convencional, desde la que se excluyen las dimensiones consideradas "personales" o "privadas". La obra de Kate Millet "Política sexual" publicada en 1969 constituirá un hito para la teoría política poniendo sobre el tapete esferas de la vida como la sexualidad y la familia, hasta entonces consideradas "personales" como locus de reproducción de sistemas de dominación (Puleo 2005).

${ }_{15}$ Véase Bell (1993), Callaway (1992), Okely (1992), Scheper-Hughes (1983) Stolcke (1996), Visweswaran (1997).

${ }^{16}$ Especialmente Behar (1995) para esta cuestión. 
dar cuenta de los aspectos emocionales ${ }^{17}$. Etnografías como la de Dube $(1975)^{18}$ han sido elogiadas por la forma de mostrar la intersubjetividad en el proceso de construcción de la etnografía. Incluso, como ha señalado Stolcke (1996) trabajos como el de Laura Bohannan ${ }^{19}$ superan en su inquietud ética y compromiso político los realizados por los antropólogos de los 80 bajo las concepciones postmodernas (1996:340).

La noción de experiencia o subjetividad que propone la perspectiva feminista poco tiene que ver con la planteada por la etnografía postmoderna. La antropología feminista, frente a la fragmentación y complejidad del sujeto postmoderno, encuentra en los procesos políticos de diferenciación el centro de su análisis, de forma que la "reflexividad que excluye lo político es en sí misma irreflexiva" (Okely 1992:4). La experiencia etnográfica, por tanto, se propone como un acto total que implica cuerpo, mente, razón y emoción de manera indisoluble y como ejercicio autoetnográfico de reconocimiento de las relaciones de poder. Es por ello, que las críticas a la etnografía postmoderna se dirigen tanto a evidenciar el ocultamiento de la generización producida en el encuentro con el "otro", como a cuestionar el vacío político y el peligro relativista que implicaría la fragmentación del sujeto postmoderno.

\section{ETNOGRAFÍA MULTILOCAL}

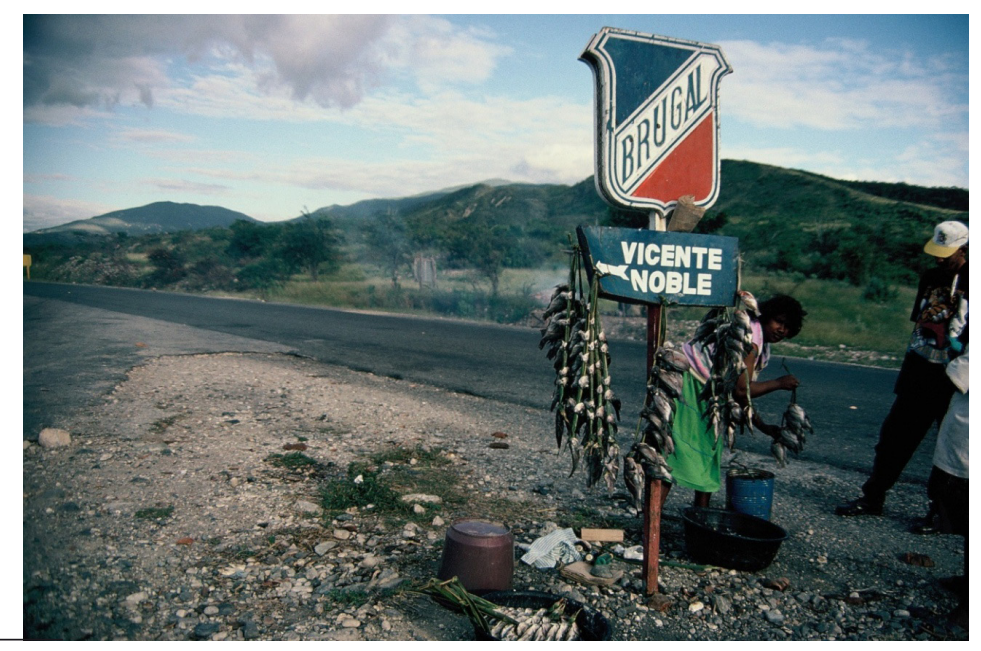

17 Es interesante incluir la opinión de Dumont (1978:12) recogida en Callaway: "Nada me parece más ficción ahora que la clásica monografía en la que un grupo humano es representado y cuarteado a través de las categorías tradicionales de lo social, lo económico, lo religioso [...] (1993:39).

${ }_{18}$ Bell, Caplan y Karim 1993 dedican su compilación a Leela Dube, de quién dicen fue una de las primeras antropólogas en considerar seriamente la relación entre el género y la etnografía.

${ }_{19}$ Se ocultó bajo el seudónimo E.S. Bowen porque no consideraba que escribía su etnografía bajo los cánones de la disciplina (Okely 1992). 
El conocido por los lugareños como "cruce de Vicente Noble", nos indica la entrada a una de las comunidades rurales donde realicé trabajo de campo en la década en los 90. En el cartel anunciador, se observa la publicidad de Brugal, una marca de ron muy apreciada por los hombres con los que tuve ocasión de compartir mi viaje etnográfico, y por otro, una mujer de piel oscura vendiendo viejaca (o tilapia), pez de agua dulce que se pesca en la lagunas de la zona y muy económico con el que a veces se suplementaban los plátanos hervidos (sancochados) que tomábamos para desayunar, tan habituales en esta economía rural de subsistencia. Las dos personas que me acompañan, mientras hacía la fotografía -aunque apenas se divisan las figuras de sus cuerpos a la derecha- me introducen en la conversación con la vendedora, quién cede a posar, sin poner ninguna objeción. ¿Acaso podría no hacerlo, cuando estaba en juego vender su mercancía y con ello aportar algunos ingresos a su hogar?

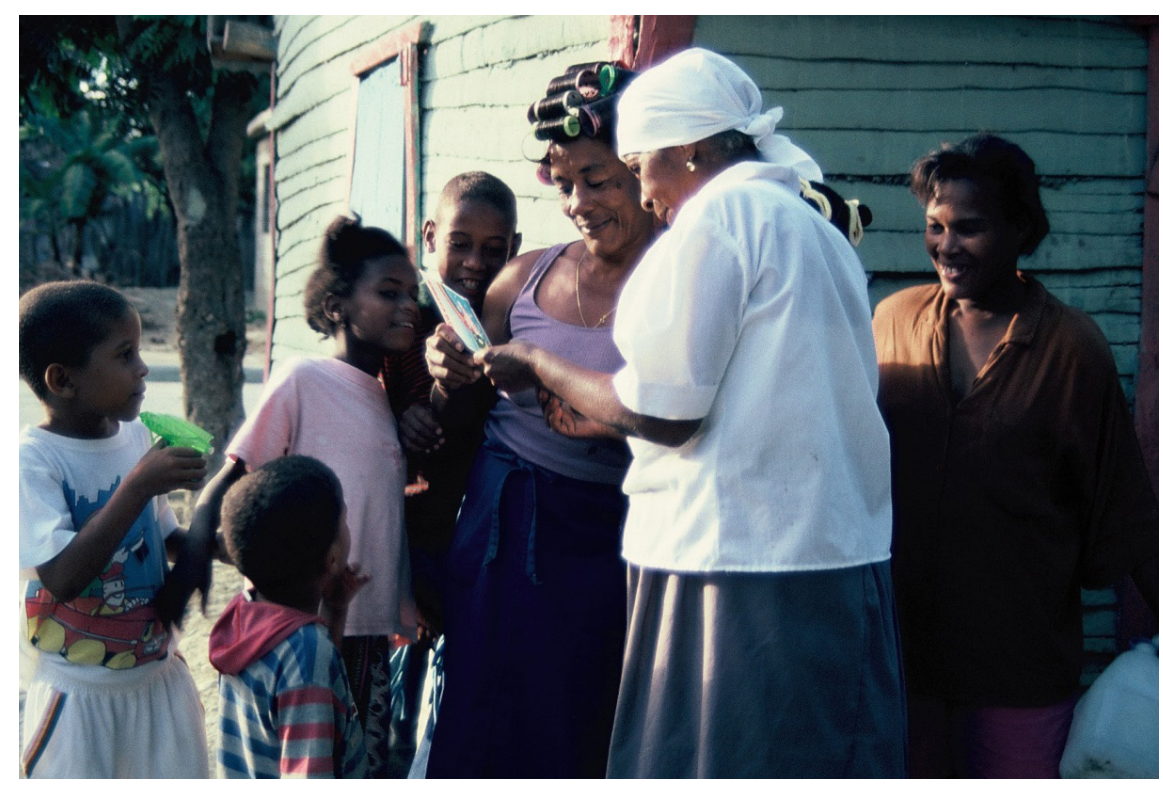

Contemplar las fotografías traídas desde la "madre patria" es todo un acontecimiento. Las sonrisas de los rostros muestran la emoción al reconocer a personas queridas, al tiempo que imaginan sus vidas en Madrid. La persona con la que viajé a Vicente Noble desde Madrid acababa de entregar a su suegra, Santica (mujer con pañuelo en la cabeza) el álbum en el que vemos la publicidad de la tienda madrileña low cost donde fueron reveladas ("Foto Express"). Santica sostiene el álbum entre sus manos mientras se las muestra a su comadre, Beko (con rolos). Detrás, una vecina, Serbella y dos de los biznietos de Santica tratan de hacerse hueco para ver las fotografías, los otros dos niños más pequeños, también biznietos, miran la escena, quizás preguntándose por el poder de evocación del objeto que sostienen entre sus manos sus mayores. Santica 
ocupa un lugar importante en la jerarquía de este grupo, ya que se ha convertido en la encargada de cuidar a la parentela de Altagracia, la mujer que emigró a España (a su esposo, así como a los hijos, nietos y nietas de ésta). Las atenciones y los agradecimientos por ello fueron constantes en el tiempo que compartí con ambas mujeres mi estancia en Vicente Noble. Las otras dos mujeres adultas mantienen con este hogar relaciones sostenidas en los cuidados mutuos que requiere el sostenimiento de la vida diaria en esta economía de subsistencia. Si bien, su posición en la escala social es inferior por lo que no disponen de bienes tan preciados como el agua potable en sus viviendas, teniendo que acudir a este hogar a coger agua de su llave de paso (de ahí la garrafa que lleva en la mano una de ellas). En esta ocasión construyo una escena que tiene lugar a nuestra llegada a Vicente Noble, a partir del álbum de fotos de la mujer emigrante mediante el que contará algunos retazos de su vida y la de sus seres queridos en Madrid y de la antropóloga, que regresa de nuevo a este $\operatorname{hogar}^{20}$ con su cámara. La convivencia continuada con Altagracia en Madrid y de nuevo en Vicente Noble con sus hijos, nietos y nietas, esposo, suegra, vecinas y comadres, me hace "ser parte de la familia" ${ }^{11}$ y poder registrar con mi cámara diferentes momentos de nuestra cotidianidad.

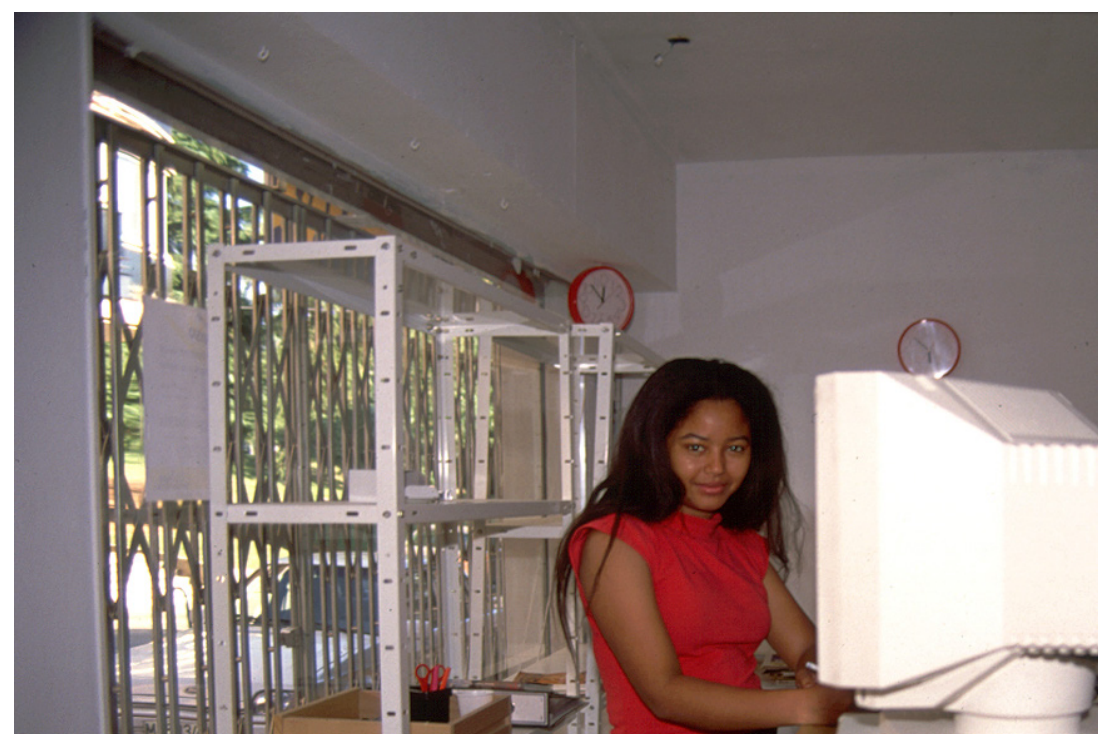

Esta joven inmigrante, de apenas 15 años, hija de una mujer con la que

${ }^{20}$ La primera vez que viajé a Vicente Noble fue en el año 1993, en esta ocasión hacía un segundo viaje a esta localidad acompañada de Altagracia para convivir por un periodo de tiempo en su hogar.

${ }^{21}$ Para un análisis de la construcción de relaciones en el campo durante mi trabajo de campo y de la tensión entre los límites de estar dentro y fuera como investigadora ver Gregorio (2014). 
habíamos compartido no pocas conversaciones en la plaza de la Corona Boreal de Aravaca y en otros espacios, posa dedicándome una sonrisa, en un locutorio, que fue pionero en los iniciados años 90 del siglo XX en ofrecer la posibilidad de realizar "videoconferencias". Conferencias, como se denominaban en estos años a las llamadas internacionales, pero con la opción de ver a las personas con la que se está hablando mediante una cámara de video instalada en el ordenador. En aquellos años, ni en Vicente Noble ni en España, disponíamos de ordenadores personales con conexión a internet wifi, ni dispositivos móviles con aplicaciones como Skype. Los pocos teléfonos móviles que había en Aravaca eran te-propiedad de algunas personas de origen dominicano que los utilizaban como fuente de ingresos, cobrando por las llamadas que hacían sus paisanas. Al fondo dos relojes de apariencia idéntica, sólo que uno marca la hora en España y el otro la hora en R. Dominicana.

Con estas fotos trato de situar al lector y lectora en los contextos donde realicé mi trabajo de campo, al tiempo que pongo mi voz (en la imagen construida mediante mi fotografía y su interpretación) a algunas de las situaciones vividas. Con ello, pretendo además, sugerir algunas de las divisiones sociales en las que enmarcaré mi análisis desde mi experiencia encarnada de género, raza y nación como etnógrafa durante mis relaciones en el trabajo de campo.

Al objeto de desvelar el orden desigualitario, encarnado en diferencias de género (y parentes $\mathrm{Co}^{22}$ ) en los procesos migratorios, me acerqué desde la metodología etnográfica a un movimiento en particular de personas, las que procedían de algunas localidades de la Región Suroeste de República Dominicana. Realicé mi trabajo de campo etnográfico siguiendo a las mujeres que emigraron desde esta región a finales de los ochenta y principios de los 90 a Madrid para trabajar en el servicio doméstico, en la modalidad de internamiento ${ }^{23}$. Mi relación con estas personas transcurrió entre diferentes lugares donde se reunían en Madrid, sobre todo en Pozuelo y en el barrio de Aravaca $^{24}$, pero también en algunas de las viviendas que compartían los fines de semana con parientes y paisanas, así como en sus hogares y localidades de

${ }^{22}$ Siguiendo la propuesta de Collier y Yanagisako (1987) y de otras autoras como Del Valle (2010) entiendo el parentesco y género como divisiones sociales inseparables. Véase Gregorio y Gonzálvez para el análisis de estas divisiones y la maternidad transnacional.

${ }^{23}$ El resultado de esta investigación puede consultarse en mi tesis doctoral Gregorio (1996) y en la publicación posterior Gregorio (1998).

${ }^{24}$ Barrio situado en el distrito de Moncloa-Aravaca del municipio de Madrid, en el que los jueves por la tarde y los domingos desde la mañana, las mujeres dominicanas procedentes sobre todo de la Región Suroeste del República Dominicana, se reunían en una de sus plazas, La Plaza Corona Boreal. Y también a Pozuelo, pueblo cercano a Aravaca, en el que una congregación religiosa impartía talleres de formación en manualidades y de alfabetización y acogía a jóvenes madres solteras en una residencia allí ubicada. Ambos lugares, pero especialmente Aravaca, se fueron convirtiendo en el punto de encuentro de estas mujeres que trabajaban como empleadas domésticas en régimen de internamiento en urbanizaciones expandidas por el Noroeste de Madrid, en las que vivía la clase alta y medio-alta madrileña. 
origen en el Suroeste de la República Dominicana, una zona rural empobrecida, muy diferente a los paraísos turísticos creados para el turismo internacional en la isla.

Siguiendo el trabajo de Marcus (1995), aun habiendo leído su trabajo posteriormente a la realización de mi investigación, describiría mi trabajo como una "etnografía multilocalizada", en tanto seguí empíricamente el hilo conductor de procesos culturales en el contexto del sistema mundo, traspasando fronteras e incorporando "la circulación de objetos, significados e identidades culturales en un tiempo-espacio difuso" (2001:111). Sin duda el tiempoespacio se difuminada: en más de una ocasión escuché decir: "se entera uno de lo que pasa en Vicente Noble antes en Aravaca, que en el propio Vicente Noble"; u observaba cómo los esposos que se habían quedado en Vicente Noble trataban de ejercer el control de sus esposas en sus llamadas telefónicas o videoconferencias. Si bien, en otras ocasiones, este tiempo-espacio se hacía angustiosamente presente, cuando los proyectos se veían frustrados por el estatus de extranjería, o lo que es lo mismo por las posibilidades de atravesar o no las fronteras, no precisamente simbólicas.

Las relaciones que establecí entonces se mantuvieron durante los cinco años que me ocupó el trabajo de campo para la realización de mi tesis doctoral (Gregorio 1996) y se prolongaron, mientras viví en Madrid tres años después, hasta finales de 1998, incluso con algunas personas se mantienen hasta el momento actual ${ }^{25}$. Las relaciones mantenidas disolvían la distancia sujetoobjeto tan preconizada desde enfoques positivistas, compartiendo momentos afectivos y de intimidad, incluso construyendo relaciones de parentesco ${ }^{26}$. Sin bien, como he expresado en otro lugar (Gregorio 2014) "en la escritura de mi tesis, presidida por la 'doctrina de la inmaculada percepción' del género etnográfico que Van Maanen ha denominado "cuentos realistas" (1988:73), omití cualquier dimensión 'subjetiva' y 'emocional' de mi proceso de trabajo de campo" (2004:303).

Releyendo mi tesis doctoral, me detengo en observar la única foto que incluí intencionadamente para representar la forma de relacionarme en el campo. Por su puesto, de todas las fotos que tengo de mi trabajo de campo elegí aquella que me otorgaba mayor 'autoridad científica' mostrando que "estaba allî" (Gregorio Gil 2014) ${ }^{27}$, la etnógrafa camuflada, que observa, escucha y toma nota en un cuaderno en una reunión de grupo en la que participa en contacto directo con esas 'otras', pero con la 'suficiente' distancia emocional de las personas con las que está compartiendo su vida. La traigo aquí de nuevo.

${ }^{25}$ En otro lugar he planteado algunos de los dilemas e interrogantes que me ha suscitado las relaciones construidas en mi práctica etnográfica al comprometer mi cotidianidad (Gregorio 2014).

${ }^{26}$ Me refiero en particular a la construcción de relaciones de compadrazgo y madrinazgo, que establecí al ser invitada como madrina de la ceremonia del bautismo.

${ }^{27}$ Idea que popularizó Geertz, "la puesta en escena literaria del contacto con el 'otro' como fruto de unas estrategias muy difundidas en la disciplina mediante las que se establecía la 'autoridad' etnográfica' sobre el conocimiento producido" (Ferrándiz 2011:24). 


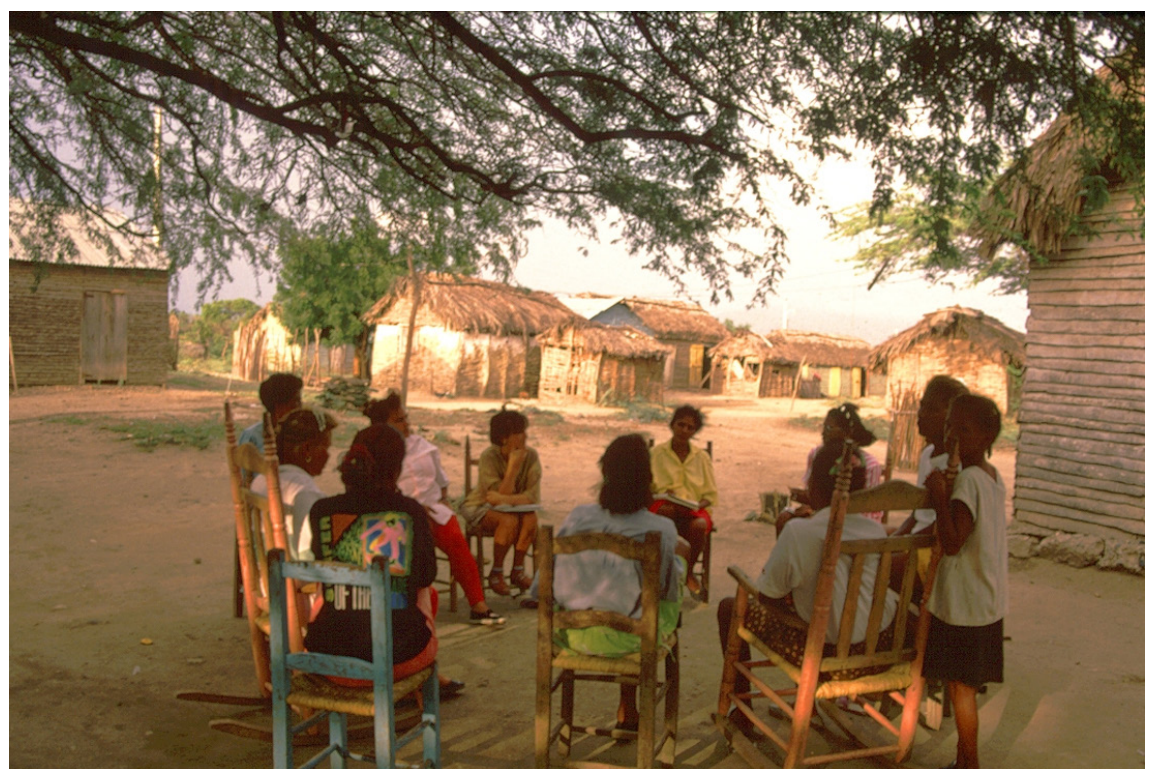

En la fotografía estoy sentada al lado de Iris, a quién conocí en Aravaca y quién, junto con su esposo que nos tomó la fotografía, me llevó a este lugar para participar en una reunión convocada por un grupo de mujeres al objeto de compartir los problemas de su vida diaria y tratar de organizarse para darles respuesta, entre otros, la falta de agua potable. Ese día además, debido a mi presencia, hablamos de la emigración que se estaba dando desde estos campos a España y de por qué eran fundamentalmente mujeres las que emigraban a España. Yo visto pantalón corto, camiseta de tonos marrones y sandalias cerradas con calcetines, lo que entre otras marcas corporales, me delata como outsider, dado lo inusual de estas prendas por parte de las mujeres, sobre todo los calcetines. Iris por su parte viste camisa rosa y pantalones ajustados (mallas), prenda esta última con la que se identificaba a las mujeres dominicanas que habían viajado a España y símbolo de la vigilada "liberación de las mujeres" de la que tanto se hablaba en esos días.

Tuvieron que pasar unos cuantos años para que desde una posición reconocida en la academia y provista de un andamiaje teórico y epistemológico bien distinto, me atreviese a conjurar el dogma que me llevó a borrar toda "mancha subjetiva" (Bell 1993) en el trabajo de campo Y desde otra perspectiva, a la que me referiré como etnografía feminista, releer mi relato etnográfico y mis documentos de campo (diarios, grabaciones y fotografías). 


\title{
4. RESTITUYENDO EL CONOCIMIENTO DESDE NUESTROS CUERPOS
}

\author{
"la etnografía, en tanto forma de conocer realidades, pasa \\ constantemente por el cuerpo mismo y por las experiencias que este vive" \\ (Pérez Bustos et al. 2016:10)
}

Desde el posicionamiento teórico y epistemológico expuesto, traeré algunas de mis vivencias haciendo uso del relato etnográfico, al objeto de restituir el valor del conocimiento desde nuestros propios cuerpos, como sujetos de acción que experimentan, sienten, se emocionan. Tomando prestadas las palabras de Jone Miren Hernández, trato de "habitar en la etnografía" para entenderla “...como experiencia de la antropóloga relacionada con actitudes culturales presentes en la sociedad y no como expresión 'del conocimiento' abstracto, impersonal, descontextualizado" (Hernández 2012: 1).

Durante mi trabajo de campo etnográfico fui tomando conciencia de las prácticas de racialización y sexualización que convertían mi cuerpo en un contenedor de significados decoloniales ${ }^{28}$. En los lugares que habité en mi etnografía mi contexto de origen (España) no era un lugar ajeno para las personas con las que me relacionaba, sino un lugar deseable para encontrar una 'vida mejor', yo vivía para ellas en un país 'rico', considerado desde concepciones geopolíticas decoloniales como su 'madre patria'. Esta deseabilidad la vivía inscrita en mi cuerpo, que además de representar a España, era sexualizado y racializado como 'mujer blanca', situándome en una posición privilegiada que parecía venir dada, al margen de mis esfuerzos, quizás demasiado ingenuos, por evitarlo.

Estudiosa del pasado colonial de República Dominicana, del sistema esclavista de Plantación que perduró hasta finales del s. XIX y de la ideología racista de la "pureza de sangre" (Stolcke 1992) legitimadora de este sistema, sin embargo, no podía imaginar, cómo mi relación con las personas durante mi trabajo de campo estaría atravesada de una forma tan intensa por la racialización y sexualización de nuestros cuerpos. Mi intersubjetividad se iba conformando desde inscripciones en mi cuerpo de raza, género, sexualidad e historia colonial.

En República Dominicana el color de piel constituye un criterio de diferenciación social, las personas en sus documentos de identidad son clasificadas en función de diferentes tonalidades de su piel (india clara, trigueña, prieta, mulata, negra, etc.). La categoría social 'raza' impregna la estructura fuertemente estratificada de la sociedad dominicana. No hay que ser muy

${ }^{28}$ Utilizo el término decolonial como hemos planteado en Gregorio y Alcázar (2014:13) en tanto propuesta teórica formulada desde América Latina por autores como Castro Gómez y Grosfoguel (2007), Mignolo (2000) y Quijano (1997) al objeto de denunciar el proceso colonial moderno como algo inconcluso. Retomamos las críticas que ha recibido la calificación de postcolonial aplicada a las relaciones actuales de dominación que mantienen los antiguos países colonialistas con las excolonias. Esta crítica se refiere, sobre todo, a la existencia misma del prefijo "post", en tanto que prefijo que presentaría las relaciones coloniales como algo superado. 
aguda para observar, cómo a pesar de la diversidad de tonalidades de piel de la población dominicana, en las regiones del país más empobrecidas o en los suburbios de las ciudades, la población es mayoritariamente de piel oscura. Una de las expresiones más extremas de racismo, hacia el 'haitiano', que en R. Dominicana se emplea como sinónimo de 'negro', son los lugares denominados bateyes $^{29}$ en los que se explota la caña de azúcar en un régimen calificado de esclavitud por diferentes organizaciones de Derechos Humanos. La piel negra en su asociación con lo "afrodescendiente" y lo "haitiano" es motivo de desvalorización, rechazo y repulsa que se expresa, tanto en las relaciones cotidianas, como en las políticas eugenésicas, en mayor o menor grado, que han venido practicando los diferentes gobiernos en la época contemporánea. Desde las políticas denominadas de "blanqueamiento de la raza" durante la dictadura de Trujillo, hasta la reciente actuación de Tribunal constitucional dominicano denunciada por la Corte Interamericana de Derechos Humanos mediante la que se despoja de su nacionalidad a decenas de miles de dominicanos y dominicanas, hijos o descendientes de ciudadanos haitianos, a pesar de haber nacido en el territorio nacional antes de la entrada en vigencia de la Constitución del año $2010^{30}$.

El rechazo hacia lo 'negro' y en oposición la hipervaloración de lo 'blanco' fue algo que impregnaba mis relaciones cotidianas con las personas en $\mathrm{R}$. Dominicana, también, aunque lo viví de forma menos encarnada, en Madrid. Para describir lo bello, el color que la gente utilizaba era el blanco y las tonalidades claras, por el contrario para mostrar disgusto o fealdad se utilizaban los términos 'prieto', 'negro' y 'haitiano'. Observé en diferentes situaciones el rechazo a las gentes del suroeste de R. Dominicana en su asociación con lo negro, lo haitiano y lo rural. Aun recuerdo con gran desagrado el comentario del taxista a quién me dirigí en Santo Domingo para preguntarle dónde podría coger los autobuses que llegaban a Vicente Noble. El taxista trató de convencerme para que me fuese con él en su taxi por un precio que acordásemos, para no ir, me dijo: "en esos transportes llenos de haitianos que hieden mal".

Mi 'blanquitud' la experimenté a partir de los diferentes significados que iba cobrando mi cuerpo en las más diversas situaciones en las que me colocaba la metodología etnográfica. Estaba familiarizada, al tiempo que indignada, con los relatos de discriminación que me compartían las mujeres dominicanas en Madrid cuando me hablaban del trato que recibían de sus empleadores y empleadoras o de los pequeños a quiénes cuidaban, así como de los y las vecinas de Aravaca ${ }^{31}$.

29 Palabra de origen taíno para denominar los lugares en los que viven los y las trabajadoras en las explotaciones agrícolas de caña de azúcar (ingenios).

30 Véase esta polémica actuación del gobierno dominicano calificada como "genocidio civil" en http://www.noticiassin.com/2013/09/el-constitucional-ignora-la-corte-interamericana/.

31 Aravaca se convirtió en lugar de encuentro para la población dominicana, especialmente la procedente de la Región Suroeste como he comentado anteriormente y fue conocido en la prensa española por el conflicto que desató esta concentración de mujeres dominicanas los jueves y domingos -días para las trabajadoras en el servicio doméstico en régimen de internamiento- entre diferentes sectores de la población aravaqueña, pero sobre todo por el lamentable asesinato de una 
El componente racial siempre aparecía en sus relatos sobre sus vivencias de discriminación. Mi convivencia con ellas hacía que me sintiese 'española' dada mi posición privilegiada, como ciudadana con derechos plenos, aunque yo para ellas era una 'española diferente', como oía decir con frecuencia: "Carmen no parece española".

Sin embargo, nunca me sentí tan 'blanca', como me sentiría meses después cuando viajé a sus comunidades de origen en R. Dominicana y viviría en mi propia carne los significados atribuidos al color de la piel. Durante mi trabajo de campo etnográfico en R. Dominicana, la 'blanquita' no pasaba desapercibida, sentía que en mi relación con los 'otros' ocupaba una posición de deseabilidad difícil de obviar. Cuando paseaba por las calles los hombres se quedaban mirándome haciendo alusiones continuas a mi 'belleza', sin mostrar ninguna contemplación a la hora de proponerme relaciones sexuales. Yo trataba de masculinizar mi cuerpo utilizando ropas anchas y no llevando maquillaje, no tanto para pasar desapercibida como antropóloga sino como 'mujer deseable', pero aún así no conseguía disminuir las invitaciones sexuales y la incomodidad que sentía con ello, que aunque fue disminuyendo nunca llegó a desaparecer. A medida que fui habitando múltiples y variadas situaciones, fui comprendiendo que la atracción la producía una combinación de significados de 'blancura' y 'españolidad' y el hecho de "caminar por la calle" en un contexto en el que el "hombre es de la calle y la mujer de la casa" (Gregorio 1996, 1998). Una mujer caminando sola, sin ir acompañada de sus hijos o sin justificar su presencia por alguna actividad relacionada con las tareas domésticas, parecía ir diciendo por la calle a los hombres que estaba disponible sexualmente. El hecho de que el esposo de una de las mujeres inmigrantes, en cuya casa estuve alojada un tiempo, me disuadiese de caminar sola por la calle, tratando de prevenirme de que fuese a algunos lugares, incluso acompañada de su hijo menor, en lugar de tranquilizarme, me produjo más inquietud, pero si cabe, también curiosidad, ¿De qué estaría tratando de protegerme? ¿Habría un peligro real o formaba parte del juego de roles y representaciones, en este caso por parte de quién pasó a considerarme 'su hija' dado el lugar de 'cuidador' que su esposa le pidió en relación a mi? Conocí a su hija en Madrid y no me era ajeno el control que su padre había ejercido sobre ella tratando de velar por su virginidad. Afortunadamente, las mujeres y los hombres con los que establecí relaciones de apoyo y complicidad en mi trabajo de campo me acompañaban en mis recorridos resignificando mi presencia como investigadora, estudiosa, pasando a ocupar esa posición ambigua en el campo que no encaja en el binarismo hombre/mujer, experiencia vivida por diferentes antropólogas en contextos y tiempos bien distintos $^{32}$.

mujer originaria de Vicente Noble, Lucrecia, en una de las viviendas desocupadas de este barrio. Pueden consultarse algunas de las noticias aparecidas en la prensa en el trabajo de Calvo Buezas (1993) "El crimen racista de Aravaca. Crónica de una muerte anunciada". Este conflicto fue objeto de interés también en esos años para las antropólogas Gladys Nieto y Adela Franzé (1997).

${ }^{32}$ Véase por ejemplo Golde (1970) o Whitehead \& Conaway (1986). 
La cercanía que establecí con algunos hombres y mujeres, me permitía comprender que mi cuerpo no respondía precisamente a su prototipo de belleza sexual. Las mujeres y hombres españoles parecíamos a los y las dominicanas 'fríos' sexualmente, por contraste ellos y ellas se definían como 'calientes'. En algunas de mis conversaciones los hombres hablaban con lascivia de los cuerpos voluminosos de las mujeres, asociándose la delgadez a enfermedad o mala alimentación consecuencia de la pobreza, yo les habría de parecer enferma porque para entonces estaba bastante delgada y aunque hacía mis pinitos cuando bailaba merengue y bachata desde luego mis movimientos de caderas se aproximaban poco a los de las mujeres dominicanas. Por tanto, todo parecía indicarme que era mi condición de española y mi piel "blanca" la que ejercía tal atracción. Me sentía una 'mujer blanca' cuando los hombres me piropeaban, pero también cuando las más pequeñas me acariciaban el cabello, fascinadas, mientras decían, “QQue pelo bueno tiene Carmen!” Pero, “¿por qué me decís eso?" les preguntaba. "A mí me encanta vuestro pelo siempre he querido tener el pelo rizado como vosotras", a lo que ellas me respondían: " ¡No! el nuestro es malo, duro”. Los moñitos con los que se peinaba a las pequeñas dejaron de parecerme tan simpáticos, cuando reparé en el ejercicio de negación y rechazo de los atributos racializados del cuerpo de estas mujeres ${ }^{33}$.

Aunque encontré resistencias en algunos sectores de clases intelectuales urbanas de izquierdas, a partir del contacto de mi cuerpo con otros cuerpos experimentaba los privilegios de ser blanca. Los significados de nuestros cuerpos estaban cargados de memoria, de las marcas de una historia de colonización, esclavismo y racismo. Traigo aquí el comentario de una mujer dominicana asentada en Madrid e investigadora de clase media-alta y con la que compartí unos días de estancia en la capital de República Dominicana (Santo Domingo) mediante el que me desvelaba su carga de rabia y denuncia. En una ocasión en que íbamos a asistir juntas a una recepción y tuve dudas acerca de si disponía del vestuario adecuado en mi equipaje, me espetó: "Vosotras las blanquitas podéis vestir como queráis, nadie os va a impedir la entrada a ningún lugar por ello".

Efectivamente, ser blanca y añadiría, española, era una 'carta blanca' para relacionarme y participar en diferentes espacios en República Dominicana vetados a la gente 'negra' y en particular a las 'mujeres negras' y todo ello a pesar de que yo intentase renunciar a tales privilegios, sufriese, me incomodase, incluso me rebelase por ello. Discutía cuando mi cuerpo era percibido en su capacidad de "blanquear la raza", con comentarios como "nuestros hijos serían bien bonitos o serían blanquitos". Me dolía el desprecio que algunas mujeres y niñas se infligían hacia sus propios cuerpos cuando se comparaban con el mío y me sentía muy tensa y frustrada cuando tomaba conciencia de que mi cuerpo

33 Es interesante traer aquí el trabajo de Candelario (2007) en el que desde sus observaciones en un salón de belleza en Washington Heights (New York) nos pone de manifiesto los significados que tiene el cabello de las mujeres como un marcador etnoracial, más importante que el color de piel, en la construcción de la identidad indohispana dominicana. En mi trabajo de campo en Aravaca las peluquerías también constituyeron uno de los espacios de observación de la producción del cuerpo a la luz de marcadores de género, raza y etnicidad (Gregorio Gil 1996). 
representaba prestigio, poder o dinero.

El color de mi piel también cobraba significados en relación con mi supuesta sexualidad, lo "blanco" se asociaba a pureza, virginidad. La sexualidad en las conversaciones con las personas con las que me relacioné en mi trabajo de campo estaba muy presente o al menos más de lo que para mí era habitual fuera de mis espacios íntimos. Tampoco parecía tener edad, tan pronto a un niño de meses, no niña, se le ponía a hacer "piquetes»", como una anciana, mientras cocinaba me hacía movimientos lascivos mientras conversábamos imaginándose el acto sexual con un hombre. Como me decía una anciana en una ocasión, "ninguna mujer se va de este mundo virgen (sin haber tenido relaciones sexuales), si eso ocurre en el cielo se le echará un burro con un enorme pene erecto". En una ocasión, cuando estábamos un grupo de mujeres bañándonos en el canal en Vicente Noble ${ }^{35}$ desnudas de torso para arriba, una mujer exclamó con admiración señalándome: “;Mírala si parece una virgencita!”. La visión de mi piel desnuda y más blanca en los lugares donde no me había dado el sol le debió parecer a esta mujer la encarnación de la virgen. Lo que me hablaba de un ideal de mujer racializada y sexualizada, del biopoder (Foucault 1978) inscrito en el cuerpo. Además de la exaltación de la blancura, el hecho de no haber tenido hijos a la edad de 28 años ${ }^{36}$ hacía que cayese sobre mí la sospecha de mi posible virginidad.

A la blancura se unían otros significados de españolidad, incluso de añoranza por la "madre patria" que me situaban en una posición privilegiada y que no hacía sino hablarme de la dominación colonial largamente ejercida en este país. Mi manera de hablar se describía como 'fina', 'biensonante', frente a la suya que era 'dura'.

Mi procedencia española y europea estuvo siempre presente en mi relación con los "otros", sentía, que ello me situaba frente a los demás, como persona deseada en tanto que podía posibilitar la movilidad social ascendente, bien dentro del propio país o facilitando la salida del mismo. Mi cuerpo representaba ese país del que llegaban las remesas de las emigrantes (España) y al que en ese momento casi todo el mundo deseaba viajar y ese país del que procedían los turistas con euros y capital social y donde residian gran cantidad de compatriotas que, en sus visitas a sus países de origen, ejemplificaban el deseado ascenso social.

Una mujer joven, blanca y española paseando sola por las calles de Vicente Noble, Tamayo o Azua en República Dominicana era algo poco común, además el que proviniese del lugar del que llegaban las remesas mi convertía en alguien deseable y para los hombres en una posible candidata a seducir y en un posible

${ }^{34}$ Movimientos de pelvis simulando una penetración.

${ }^{35}$ El canal de riego que atravesaba el núcleo urbano era utilizado por la gente para bañarse, dado que muchas viviendas carecían de agua corriente y, como consecuencia de los cortes de luz, eran frecuentes los cortes de agua. Las mujeres nos bañábamos en un lugar y los hombres en otro y normalmente en momentos distintos.

${ }^{36}$ En esta región un número elevado de mujeres comienzan su ciclo reproductivo a los 14 y 15 años no existiendo prácticamente separación entre la sexualidad y la procreación. 
contacto para posibilitar la emigración a España o proporcionar algunos dólares siempre bienvenidos en una economía rural de subsistencia.

El corazón se me sigue encogiendo cuando rememoro las lúcidas palabras que Santica pronunció al verme quince años después de mi último viaje a Vicente Noble $^{37}$, a pesar de su diagnóstico de enajenación mental después de haber sufrido varios ictus cerebrales. Me esperaban en la casa, yo había comunicado por teléfono el día de mi llegada y también Altagracia había avisado. Cuando llegué, Santica desde su silla en la que estaba sentada en el rellano de la puerta me miró fijamente a los ojos y como si hubiese sido una aparición divina, lo primero que me dijo fue: "no tengo medicinas". Sus nietos y biznietos que la rodeaban, sorprendidos de que me hablase le preguntaron “ ¿pero la conoce mae?", a lo que ella respondió pausadamente "; Y claro Carmen, la española!". Para ella yo Yo era 'la española', o lo que es lo mismo en ese momento crítico de su existencia quién podría proveerle las medicinas con las que poder aliviarse.

Al objeto de ponerle vida a este relato, traigo aquí una fotografía de Santica, de esa mirada que siempre me conmovió, esa mezcla de cansancio, sabiduría, espera y rebeldía. Con ella, dos de sus biznietos, quiénes durante mi estancia no dejaron de estar a su lado prodigándole atenciones y cuidados.

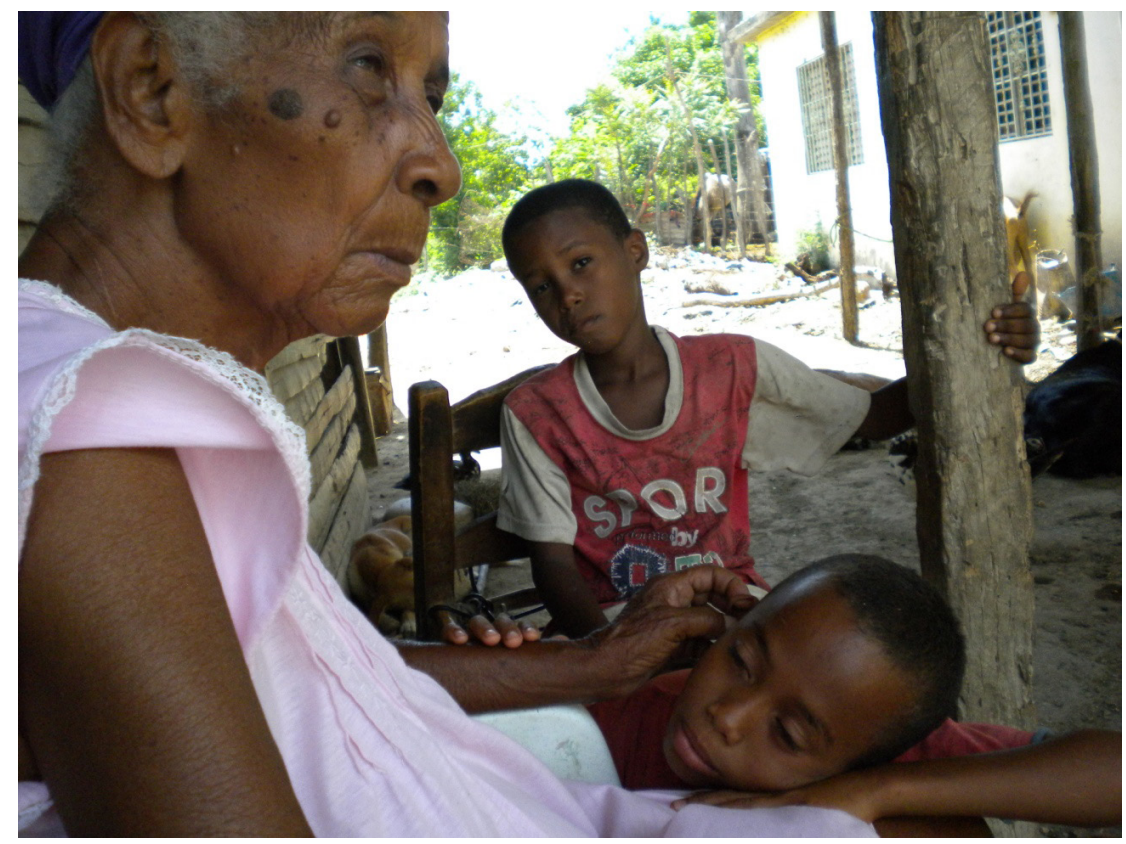

37 Mi última estancia de trabajo de campo en Vicente Noble la había realizado de enero a marzo de 1995, en agosto del año 2010 volví a visitar a las personas con las que había seguido manteniendo un vínculo a través de sus familiares en España (Gregorio Gil 2014). 
El impacto de la emigración a España en las comunidades donde realicé el trabajo de campo era tal, que sólo el hecho de mi presencia se relacionaba automáticamente con la 'madre patria' ahora convertida en patria 'acogedora' de las personas emigrantes. Recuerdo que uno de mis primeros días en el pueblo de Tamayo, cuando paseaba por la calle, una mujer que iba montada en una bicicleta me gritó sin bajarse de la bici y sin que yo cruzase ni una sola palabra con ella "Yo fui dos veces a España y me devolvieron". Mi cuerpo, simbolizaba el nexo de unión entre las personas migrantes y sus familiares. Otro día, mientras conversaba con un grupo de personas, éstas comenzaron a hablar de un hombre que tenía a varios familiares en España, “'Estando tú aquí y no han venido ni a preguntar por ellas!" decían sorprendidas. Quince años más tarde, mientras cogía el autobús que me llevaría a Vicente Noble en Santo Domingo, uno de los vendedores que entraban en los autobuses nada más verme empezó a decirme "tía”, "joder", imitaba un argot que rápidamente identifiqué como madrileño.

En una economía en la que las relaciones de reciprocidad son muy importantes para la reproducción de los hogares y en donde mujeres como Santica invocaban a los dioses para que apareciesen las viandas con las que hacer la comida diaria para unas 20 personas, las peticiones de dinero "a la española" no se dejaban esperar. Más allá de que yo hiciese todo lo posible para no tratar de reforzar la idea de la española rica, por más precaria que fuese entonces mi situación económica, por más vulnerable y estúpida que me sintiese en no pocas ocasiones, sentía, que por el simple hecho de existir, se me otorgaba un lugar de poder y prestigio.

\section{PARA CONCLUIR: EL VALOR DE LA INTERSUBJETIVIDAD DESDE POSICIONES POLÍTICAS SITUADAS}

Propongo la etnografía feminista como forma de disolver las fronteras entre 'sujeto-conocedor/a' y 'objeto -de conocimiento-', entre un 'yo' y un 'otro', para tomar un camino dialógico e intersubjetivo como fuente de conocimiento desde posiciones políticas situadas. Un camino que pone en el centro la experiencia etnográfica de nuestro cuerpo en relación con los otros cuerpos y como ejercicio autoetnográfico de reconocimiento de las relaciones de poder.

Desde una crítica feminista la toma de conciencia de que el propio acto de categorizar a quiénes estudiamos supone una expresión de poder, nos obliga a cuestionar las categorías fijas e inmutables que asignamos. Lo que lleva implícito un ejercicio de deconstrucción de la noción de identidades como categorías fijas y monolíticas que actúan en el campo, para proponer la noción de persona que experimenta y se transforma, en las relaciones con los otros (Strathern 1988). Siguiendo a De Lauretis (1986) trato de transcender la noción de persona unitaria dualizada, como mujer o hombre y conceptualizó la identidad en el proceso de intersubjetividad etnográfico como múltiple, situada y contestada, al tiempo que contradictoria. Habito en mi etnografía desde la 
experiencia encarnada y multisituada para convertirla en fuente de conocimiento mediante el que denunciar los regímenes de verdad y de poder decolonial, racial, sexual.

\section{BIBLIOGRAFÍA}

ABU-LUGHOD, L. (1990): “Can There Be A Feminist Ethnography?”, Women and Performance: A Journal of Feminist Theory, 5, pp. 7-27.

BEHAR, R. (1995) “Introduction: Out of Exile" en Women Writing Culture, University of California Press, London, pp 1-32

BELL, D. (1993) "Introduction 1: The Context", en Gendered fields. Women, Men and Ethnography. London, Routledge, pp. 1-18.

BELL, D., CAPLAN, P. \& WAZIR JAHAN, K. (eds.) (1993): Gendered Fields. Women, Men \& Etnography, London, Routledge.

CALLAWAY, H. (1992) "Ethnography and Experience. Gender Implications in Fieldwork and Texts", en Anthropology \& Autobiography, London, Routledge, pp. $29-49$

CALVO BUEZAS, T. (1993): El crimen racista de Aravaca. Crónica de una muerte anunciada, Madrid, Editorial Popular.

CANDELARIO, G. (2007): Black behind the Ears: Dominican Racial Identity from Museums to Beauty Shops, Durham, Duke, University Press.

CARRASCO, C. (2003): "El cuidado: ¿coste o prioridad social?”, Ponencia presentada en el Congreso Internacional Cuidar cuesta: costes y beneficios del cuidado, Donostia, 13 y 14 de octubre de 2003.

COLLIER, J.F. \& YANAGISAKO, S. Y. (1987): “Introduction", en Gender and Kinship. Essays Toward a Unified Analysis, Stanford, California, Stanford,University Press:1-13

COMAS, D. (1995): Trabajo, género, cultura: la construcción de desigualdades entre hombres y mujeres, Barcelona: Icaria.

DALY, M. \& LEWIS, J. (1999): "The Concept of Social Care and the Analysis of Contemporary Welfare States", British Journal of Sociology, 51 (2), pp. 281-298

DE LAURETIS, T. (1986) Feminist Studies/Critical Studies: Issues, Terms, and Contexts, en Feminist Studies/Critical Studies, Bloomington, Indiana University Press, pp. 1-19.

DEL VALLE, T. (2003): "Contenidos y significados de nuevas formas de cuidado", Ponencia presentada en el Congreso Internacional Cuidar cuesta: costes y beneficios del cuidado, Donostia, 13 y 14 de octubre.

Del VALLE, T. (ed.) (2000): Perspectivas feministas desde la antropología social, Barcelona. Ariel Antropología.

Del VALLE, T (2010): "La articulación del género y el parentesco desde la antropología feminista", en Procreación, crianza y género. Aproximaciones antropológicas a la parentalidad, Barcelona, PPU, pp. 395-218.

FERRÁNDIZ, F. (2011): Etnografías contemporáneas. Anclajes, métodos y claves para el futuro, Barcelona, Anthropos.

FOUCAULT, M.(1978): Vigilar y castigar: nacimiento de la prisión, Madrid, Siglo XXI.

GILLIGAN, C. (1982): In a Different Voice: Psychological Theory and Women's Development, Harvard, University Press. 
GOLDE, P. [1970] (1986) Women in the Field. Anthropological Experiences, Berkeley, California. University of California Press.

GREGORIO GIL, C. (1996): Sistemas de género y migración internacional. La emigración dominicana en la Comunidad de Madrid, Tesis doctoral, Departamento de Antropología social, Universidad Autónoma de Madrid.

GREGORIO GIL, C. (1998): Migración femenina. Su impacto en las relaciones de género, Madrid, Narcea.

GREGORIO GIL, C. (1999) "Los movimientos migratorios del Sur al Norte como procesos de género", en Globalización y Género, Madrid, Editorial Síntesis, pp. 259-288.

GREGORIO GIL, C. (2002) "Mujer, española, blanca, rica... Trabajo de campo en inmigración y relaciones de género", en Las migraciones a debate, de las teorías a las prácticas sociales, Barcelona, Icaria, pp. 315-345.

GREGORIO GIL, C. (2006) "Contribuciones feministas a problemas epistemológicos de la disciplina antropológica: Representación y relaciones de poder", AIBR. Revista de Antropología Iberoamericana, 1 (1), pp.22-39

GREGORIO GIL, C. (2006b)"Bailarinas y amas de casa": divisiones sociales en el mercado transnacionalizado y representaciones de género, Tiempos de América: Revista de historia, cultura y territorio,13, pp. 109-120

GREGORIO GIL, C. (2009): "Políticas de conciliación, externalización del trabajo doméstico y de cuidados y migraciones transnacionales, en III Congreso de Economía Feminista, 2y3 abril, Baeza.

GREGORIO GIL, C. \& CASTAÑEDA SALGADO, M. P. (2012): Mujeres y hombres en el mundo global. Antropología feminista en América Latina y España. México, Siglo XXI.

GREGORIO GIL, C. (2014): “Traspasando las fronteras dentro-fuera: reflexiones desde una etnografía feminista, Revista de Antropología Iberoamericana, 9 (3): 297-322

GREGORIO GIL, C y GONZALVEZ TORRALBO, H. (2012): "Las articulaciones entre género y parentesco en el contexto inmigratorio: más allá de la maternidad transnacional", Ankulegi, 16:43-57

GREGORIO GIL, C. \& ALCÁZAR CAMPOS, A. (2014): Trabajo de campo en contextos racializados y sexualizados: cuando la decolonialidad se inscribe en nuestros cuerpos, Gazeta de Antropología, 30(3),pp. artículo 01.

HERNÁNDEZ GARCÍA, J. M. (2012): La autoetnografía como habitáculo. Espacios para vivir y compartir. Texto inédito presentado para el proyecto FEM2009-10982, diciembre 2012.

LETABLIER, M.T (2007): "El trabajo de "cuidados" y su conceptualización en Europa", en Trabajo, género y tiempo social, Madrid, Hacer, pp. 64-84.

LUGONES, M. (2007): "Heterosexualism and the Colonial / Modern Gender System", Hypatia, 22 (1), pp. 186-209

MARCUS, G. (2001):“Etnografía en/del sistema mundo. El surgimiento de la etnografía Multilocal”, Alteridades, 11 (022), pp. 111-127.

MARTIN PALOMO, T. (2009) "El care un debate abierto: de las políticas de tiempos al social care, Cuestiones de género: de la igualdad y la diferencia, 4, pp.325-355

MENDEZ, L. (2007): Antropología feminista, Madrid, Síntesis

MOORE, H.L. (1991): Antropología y feminismo, Madrid, Cátedra.

NIETO, G. Y FRANZÉ, A. (1997): "The Projection of Social Conflict Through Urban Space: The Plaza de la Corona Boreal”, Current Anthropology, 38 (3), pp. 461-466. 
NAROTZKY, S.(1995): Mujer, mujeres, género. Una aproximación crítica al estudio de las mujeres en las Ciencias Sociales, Madrid, Consejo Superior de Investigaciones Científicas.

OKELY, J. (1992) “Anthropology and Autobiography: Participatory Experience and Embodied Knowledge”, en Anthropology \& Autobiography, London, Routledge, pp. 1-28.

PULEO, A. H (2005): "Lo personal es político: el surgimiento del feminismo radical, en Teoría feminista: de la ilustración a la globalización, Madrid, Minerva, pp. 35-67

PÉREZ OROZCO, A. (2006): “Amenaza tormenta: la crisis de los cuidados y la reorganización del sistema económico", Revista de economía crítica, 5, pp. 7-37

PÉREZ-BUSTOS, T., TOBAR-ROA, V. \& MÁRQUEZ-GUTIÉRREZ, S. (2016) "Etnografías de los contactos. Reflexiones feministas sobre el bordado como conocimiento", Antípoda, Revista de Antropología y Arqueología, 26, pp.47-66

SCHEPER-HUGHES, N. (1983): "The Problem of Bias in Androcentric and Feminist Anthropology”, Women's Studies, 10, pp. 109-116

STACEY, J (1988)“Can There Be a Feminist Ethnography?", Women Studies International Forum, 11 (1), pp.21-27

STOLCKE, V. (1996): “Antropología del género. El cómo y el por qué de las mujeres”, en Ensayos de antropología cultural, Barcelona, Ariel, pp. 335-343.

STRATHERN, M. (1998): "Fuera de contexto. Las ficciones persuasivas de la antropología", en El surgimiento de la antropología posmoderna, Barcelona, Gedisa Editorial, pp. [1987 "Out of context: the persuasive fictions of anthropology" Current Anthropology, 28 (3) 1-77.]

THURÉN, B.M. (1993): El poder generizado. El desarrollo de la antropología feminista, Madrid, Instituto de Investigaciones Feministas, Universidad Complutense de Madrid y Dirección General de la Mujer.

VACCHHIANO, F. (2015): "Los hundidos y los salvados. Reflexiones sobre movilidad y frontera en tiempo de crisis", Revista de Dialectología y Tradiciones PopularesRDTP, Vol LXX (2), pp. 315-323

VISWESWARAN, K. (1997): "Histories of Feminist Ethnography”, Annual Review of Antrhopology, 26, pp.591-621.

WHITEHEAD, T. L. \& CONAWAY, M.E. (eds.) (1986): Self, Sex and Gender in Cross-Cultural Fieldwork, Chicago, University of Illinois Press. 
